\title{
LOS DERECHOS HUMANOS COMO ADQUISICIÓN EVOLUTIVA*
}

\author{
Mauro Barberis \\ Universidad de Trieste
}

RESUMEN. Este ensayo trata de mostrar la aplicabilidad de un enfoque evolucionista a la cuestión aparentemente más ajena a ello: los derechos humanos. El primer apartado esboza los rasgos metodológicos y metaéticos de un enfoque de la ética en general, y de los derechos humanos en particular, inspirado por el subjetivismo económico de la Escuela austríaca: un enfoque genéricamente positivista, pero específicamente evolucionista. El segundo apartado formula algunas hipótesis históricas sobre los orígenes y la evolución de los derechos humanos en la tradición ética y jurídica occidental. El tercer apartado, finalmente, refina algunas herramientas teóricas para el análisis de la interpretación constitucional de los derechos humanos, como valores institucionalizados por principios y garantizados por reglas.

Palabras clave: derechos humanos, positivismo jurídico, evolucionismo.

\section{Human Rights as an Evolutionary Acquisition}

ABSTRACT. Human rights, a traditionally intractable subject to legal positivism, are analyzed here with a generally positivist, but specifically evolutionist approach - a distinction is drawn, in fact, between a merely evolutionary and a full-blown evolutionist one- - . The first section sketches methodological and metaethical aspects of such an approach, specifically inspired by the economic subjectivism of Austrian School and then articulated by B. LEONI and F. HAYEK's works without any reference to human rights. The second section proposes some historical hypotheses about the origins and the evolution of rights in the ethical and legal Western tradition. The third and last section refines some theorethical tools for the analysis of constitutional interpretation, distinguishing ethical values, constitutional principles and statutory rules.

Keywords: human rights, legal positivism, evolutionism.

\footnotetext{
* Fecha de recepción: 12 de julio de 2013. Fecha de aceptación: 23 de septiembre de 2013.
} 


\section{Por la evolución, lo improbable} se convierte en probable

(N. LUHMANN)

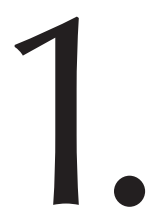

Los derechos humanos siguen siendo un verdadero desafío para la tradición del positivismo jurídico: quizá no para el positivismo metodológico, la actitud avalorativa frente al derecho, pero sí para el llamado positivismo teórico. Como lo dice de manera tajante M. TROPER: si «la expresión "derechos humanos" designa derechos que el ser humano tendría y ejercería independientemente del Estado [...] entonces, desde el estricto punto de vista positivista, el problema queda [...] rápidamente resuelto: no hay derechos humanos» ${ }^{1}$. Los tres apartados de este trabajo querrían mostrar que el desafío puede ser afrontado por un particular enfoque positivista que llamaré evolucionista: un enfoque hasta hoy difundido casi exclusivamente en el ámbito del common law, e incluso allí aparentemente ajeno a la materia de los derechos humanos.

En el primer apartado trataré de esbozar los rasgos metodológicos y metaéticos de un enfoque sobre la ética en general y los derechos humanos en particular inspirado por el subjetivismo económico de la Escuela austríaca ${ }^{2}$ : enfoque que sigue siendo genéricamente positivista, pero que adopta una epistemología específicamente evolucionista. En el segundo apartado formularé algunas hipótesis históricas sobre los orígenes y la evolución de los derechos humanos en la tradición ética y jurídica ocidental. En el tercer apartado, finalmente, intentaré refinar algunas herramientas teóricas para el análisis de la interpretación constitucional de los derechos humanos, como valores institucionalizados por principios y garantizados por reglas.

\section{EL ENFOQUE EVOLUCIONISTA}

Todos sabemos qué es el evolucionismo: la revolución científica llevada a cabo en la biología por Charles Darwin que supera el paradigma creacionista mostrando que todas las especies vivas son el producto de la evolución. Los mecanismos de este proceso milenario, formulados en términos de la síntesis entre darwinismo y leyes de la genética, son básicamente tres: 1) mutación genética casual; 2) selección de las mutaciones aptas al medio ambiente; 3 ) retención de las mutaciones favorables a la supervivencia. En esta sección pretendo solo, primero, recordar algunos rasgos del evolucionismo cultural, después, trazar algunos rasgos de la metodología de la Escuela austríaca de economía, que constituye una extensión del evolucionismo natural al mundo social, y finalmente extraer de esta reconstrucción algunas consecuencias para el conocimiento del derecho y de los derechos.

1 Así M. Troper, «Le positivisme et les droits de l'homme», en V. Champeil-Desplats y N. Ferré (dirs.), Frontières du droit, critiques des droits, Paris, LGDJ, 2007, 233.

2 Cfr. P. BARROTTA (a cura di), Soggettivismo, tempo e istituzioni a partire dalla Scuola Austriaca, Soveria Mannelli (CZ), Rubbettino, 2005. 
1. En cuanto al evolucionismo cultural, es importante recordar que el propio evolucionismo natural tiene sus orígenes en los moralistas escoceses del siglo XVIII como D. Hume y A. SMITH. Son estos autores quienes formulan las ideas de mano invisible y de efectos no intencionales de la acción humana intencional ${ }^{3}$ : ideas después proyectadas por DARWIN sobre el mundo natural, donde la mutación casual y la retención selectiva juegan el papel que en el pensamiento escocés desempeñan los actos intencionales y los efectos no intencionales respectivamente ${ }^{4}$. La clara contribución de los escoceses a la formación del contexto de descubrimiento del evolucionismo natural, sin embargo, no resuelve los problemas metodológicos que se encuentran en el contexto de justificación, y en particular los siguientes.

Por supuesto, el rasgo común a toda metodología evolucionista es la evolución por oposición a la creación: el descubrimiento de un mecanismo de adaptación de los seres vivos al medio ambiente que explica el origen y el funcionamiento tanto de las especies biológicas como de las instituciones sin recurrir a la intervención de un creador, ni divino ni humano. Sin embargo, muchas aplicaciones del evolucionismo al mundo social, en particular en el siglo XIX, se han caracterizado por incurrir en tres distorsiones comunes de la metodología evolucionista: el naturalismo, es decir, la reducción de lo cultural a lo natural; el determinismo, la idea que todo puede ser explicado causalmente; el historicismo, en el sentido subrayado por K. POPPER de la creencia en leyes férreas de la evolución.

Todas estas distorsiones pueden ser consideradas, ya en las ciencias naturales, como reducciones del evolucionismo a una forma obsoleta de positivismo científico, y de hecho son criticadas por la escuela austríaca. El historicismo y el determinismo son criticados porque los fenómenos naturales y sociales son demasiado complejos como para permitir más que conjeturas sobre ellos, y el naturalismo por la razón siguiente, evidentemente más importante: las explicaciones en las ciencias sociales, a diferencia que de lo que sucede en las ciencias naturales, deben tomar en cuenta las intenciones, los diseños y hasta la libertad humana, concebida no como postulado metafísico sino como efecto de la limitación de la racionalidad ${ }^{5}$. Precisamente en la solución del problema de la contribución intencional a la evolución consiste, creo, la más importante aportación austríaca.

2. La Escuela austríaca ha proporcionado una fecunda extensión de la metodología evolucionista al mundo de la cultura: una extensión no reduccionista sino explícitamente crítica del naturalismo, del determinismo y del historicismo. El carácter específicamente evolucionista de la metodología austríaca, desde el fundador C. MENGER hasta su más conocido representante, F. VON HAYEK, pasando por L. vON MISES $^{6}$, ha sido explicitado por HAYEK en la segunda mitad del siglo pasado con su oposición entre evolucionismo (evolutionism) y constructivismo (constructivism). El carácter evolucionista de esta metodología era, sin embargo, ya desde el inicio evidente

3 R. Boudon, Effets pervers de l'action sociale, Paris, Puf, 1977.

4 A. FLEW, «Social Science: Making Visible the Invisible Hands», The Journal of Libertarian Studies, $1987,8,197-211$.

5 H. A. Simon, Reason in Human Affairs, Stanford, Stanford U. P., 1983.

6 R. Cubeddu, The Philosophy of the Austrian School, London, Routledge, 1993; A. Masala, Crisi e rinascita del liberalismo classico, Pisa, Ets, 2012. 
en la teoría subjetivista del valor, una contribución austríaca olvidada quizá demasiado rápidamente por la metaética analítica del siglo Xx (cfr. aquí, 3.1).

La idea de Menger, principal metodólogo de las ciencias sociales antes de M. WEBER, es que «el lenguaje, la religión, el derecho, incluso el Estado» ${ }^{7}$, pueden ser explicados como efectos no intencionales, de agregación o de composición, de actos humanos intencionales. El ejemplo más simple es la formación de los precios: por medio de la negociación en el mercado, las evaluaciones subjetivas, es decir, los valores de uso, se convierten en valores de cambio objetivos o intersubjetivos. De esta manera se forman los valores, la normas y las instituciones, en una palabra, la cultura: ésta «no es ni natural ni artificial, ni transmitida genéticamente ni racionalmente proyectada» ${ }^{8}$. A menudo, los austríacos piensan que las instituciones humanas pertenecen a un Tercer Reino (G. FreGE) o Mundo Tres (K. POPPER) de objetos culturales.

El modelo evolucionista austríaco de la formación de los valores puede ser generalizado a todo el mundo humano, como muestran tres ejemplos: uno lingüístico, otro político y otro jurídico. Un ejemplo lingüístico podría ser la famosa caracterización del discurso ordinario hecha por J. LANGSHAW AUSTIN: caracterización que cito aquí sólo porque le debo mi primer encuentro con el evolucionismo. «Our common stock of words - dicen AustIN, y H. HART quien lo cita- embodies all the distinctions men have found worth drawing, and the connections they have found worth marking, in the lifetimes of many generations: these surely are likely to be more numerous, more sound, since they have stood up to the long test of the survival of the fittest $\gg$ ?.

Un ejemplo político podría ser la explicación fundamental —es decir, de una esfera cultural a partir de otra- del Estado a partir de la competencia entre agencias de protección según NOZICK ${ }^{10}$. Por supuesto, las cosas podrían haber sido diferentes; sin embargo, los Estados modernos, como Inglaterra, Francia y España, pueden ser verdaderamente explicados como el producto de procesos de selección entre poderes feudales en conflicto. Un ejemplo jurídico, finalmente, podría ser la famosa teoría de HuME del origen de la propiedad a partir de la convención de respetar las posesiones de los demás; aquí, sin embargo, utilizaré la teoría del derecho como pretensión de B. LEONI (cfr. 2.4): teoría inspirada directamente por el evolucionismo austríaco, inspirado a su vez por Hume.

3. En cuanto a las aplicaciones jurídicas del enfoque evolucionista, hay que decir que hasta hoy han sido bastante parciales y discutibles, de modo que es preferible ser rigurosos con la literatura y atribuir cada tesis a su preciso autor. De antemano sería importante distinguir entre un enfoque genéricamente evolutivo y otro específicamente evolucionista. De hecho, bajo la etiqueta «derecho y evolución», toda la literatura sociológica e incluso jurídica podría ser calificada como evolutiva: toda, en efecto,

7 C. MENGER, Sul metodo delle scienze sociali (1883), trad. it. de Untersuchungen über die Methode der Sozilwissenschaften, Macerata, Liberilibri, 1996, 150.

${ }^{8}$ F. HAYEK, Legge, legislazione e libertà, trad. it. de Law, Legislation and Liberty (1982), Milano, Il Saggiatore, $1989,531$.

9 J. L. Austin, A Plea for Excuses, en id. Philosophical Papers, Oxford, Oxford U. P., 182.

10 R. NozIcK, Anarchia, Stato e utopia, tra. it. de Anarchy, State and Utopia (1974), Firenze, Le Monnier, 1974. 
habla genéricamente del cambio jurídico ${ }^{11}$. Sin embargo, hay también una literatura filosófico-jurídica evolucionista en el sentido darwiniano del término: por citar sólo los libros, y dejando aparte las contribuciones de la Escuela austríaca y sobre ella, esa literatura incluye al menos ocho títulos ${ }^{12}$, de autores no siempre, es cierto, tan interesados por el derecho como por la evolución.

Si en la literatura evolucionista los derechos humanos están ausentes, en la austríaca son considerados poco más que declamaciones retóricas peligrosas para las libertades individuales ${ }^{13}$ : las más importantes contribuciones austríacas al derecho, Freedom and the Law (1961) de B. LEONI ${ }^{14}$, y Law, Legislation and Liberty (1982) de F. HAYEK, hablan de los derechos humanos sólo para criticarlos. La monumental obra de HAYEK menciona los derechos humanos una sola vez, y para criticar la Declaración universal de los derechos bumanos (1948) por incluir derechos sociales: es el verdadero modelo (negativo) de los derechos humanos en toda esta literatura. Veremos como el propio LEONI proporciona un modelo de la formación del derecho objetivo a partir de pretensiones subjetivas, pero sin hablar de derechos humanos.

La relación entre evolución y derechos humanos podría ser esbozada así. Los sistemas éticos (morales, políticos y jurídicos...) se forman como los mercados, es decir a partir del encuentro de actos intencionales individuales que generan, por efecto no intencional de agregación o composición, instituciones complejas. La ética y la interpretación jurídica tienen así dos rasgos: el rasgo subjetivo del acto intencional individual de evaluación moral, sea de pretensión o de interpretación jurídica y constitucional, y el rasgo objetivo de la actividad, como conjunto de actos que producen valores y normas relativamente estables. La metaética subjetivista y la teoría de la interpretación escéptica del siglo XX, creo, han pasado por alto el segundo rasgo: sin entender que sólo en el contexto del segundo el primero tiene sentido ${ }^{15}$.

El derecho moderno ha sustituido la producción consuetudinaria de normas con la legislación, y la interpretatio iuris - la búsqueda de la solución del caso por la iurisprudentia o por el juez-con la interpretación de la ley. Esta es concebida subjetivamente como el acto de atribución de sentido a un texto por los intérpretes, acto orientado a su aplicación; sin embargo, se puede también entender objetivamente, como la activi-

${ }_{11}$ Cfr. al menos P. STEIn, Legal Evolution. The Story of an Idea, Cambridge, Cambridge U. P., 1980, y A. Watson, Legal Evolution, Baltimore, John Hopkins U. P., 1985.

${ }_{12}$ Cfr. J. H. Beckstrom, Evolutionary Jurisprudence. Prospects and Limitations on the Use of Modern Darwinism throughout the Legal Process, Urbana and Chicago, University of Illinois Press, 1979; M. BARBERIS, L'evoluzione nel diritto, Torino, Giappichelli, 1998; S. DEAKIN, Evolution of Our Time: a Theory of Legal Memetics, Oxford, Oxford U. P., 2003; E. OESER, Evolution and Costitution. The Evolutionary Self-Construction of Law, Dordrecht, Reidel, 2003; A. C. HutCHInson, Evolution and the Common Law, Cambridge, Cambridge U. P., 2005; W. ZALuski, Evolutionary Theory and Legal Philosophy, Cheltenham, Elgar, 2009; M. ZAMBONI, Evolutionary Theory and Legal Positivism. A Possible Marriage, 2010, bttp:works.bepress.com/mauro_zamboni/8; F. RomeO, Antropologia giuridica. Un percorso evoluzionista verso l'origine della relazione giuridica, Torino, Giappichelli, 2012.

13 D. B. RAsmussen, «A Groundwork for Rights: Man's Natural Ends», The Journal of Libertarian Studies, 1980, 4, 65-94; F. VAN DuN, «Human Dignity: Reason or Desire? Natural Rights versus Human Rights», The Journal of Libertarian Studies, 2001, 15, 1-28.

14 B. LEONI, Freedom and the Law, Princeton, Van Nostrand, 1961.

15 M. BARBERIS, «Interpretación-acto e interpretación-actividad. Nueves extensiones de la teoría genovesa», en prensa para Revista brasileira de filosofía, 2013. 
dad que los autores norteamericanos llaman legal process ${ }^{16}$ : una división del trabajo de producción del derecho entre diferentes sujetos típicos. A este proceso, en el llamado Estado legislativo, participan con papeles diferentes legisladores, jueces y doctrina ( $c f r$. aquí 3.3): a los cuales hace falta añadir, en el llamado Estado constitucional, a los constituyentes y la justicia constitucional ${ }^{17}$.

Sin duda, si se pasa por alto todo esto se puede trazar una distinción dicotómica entre derecho natural y positivismo jurídico: como lo hacen HART, proporcionando el criterio dicotómico de la conexión necesaria o contingente entre derecho y moral, y V. VILLA, con su definición conceptual de «positivismo jurídico» ${ }^{18}$. Sin embargo, se puede admitir que hay otros criterios distintivos: considerar el derecho como una razón para la acción, la relevancia de la naturaleza humana para los contenidos del derecho, la diferencia entre conocimiento y evaluación, la juridicidad del derecho natural ${ }^{19}$. Sobre todo, si tomamos suficientemente en serio la convencionalidad del lenguaje, ordinario y teórico, siempre podemos adoptar otras definiciones de los términos teóricos, e incluso distinciones no dicotómicas entre derecho natural y positivismo jurídico ${ }^{20}$.

Por ejemplo, si para distinguir derecho natural y positivismo jurídico adoptamos el conocido criterio de las fuentes sociales del derecho ${ }^{21}$, entonces podemos distinguir al menos tres teorías: el derecho natural (el derecho se encuentra en la naturaleza o en la razón humana); el positivismo estándar (el derecho es efecto de actos humanos intencionales); el evolucionismo (el derecho es efecto de actos intencionales individuales y de actividades o agregaciones de efectos no intencionales de actos intencionales). Sin embargo, el evolucionismo está más cerca de la tradición positivista, por al menos cinco (o seis) razones. La primera es la adopción del principio de la Wertfreibeit, la actitud avalorativa frente al derecho o positivismo metodológico: actitud respetada, en verdad, más por los biólogos que por los positivistas teóricos de los siglos pasados.

La segunda razón es la superación del paradigma científico empirista o neoempirista que suponía el positivismo teórico: un paradigma superado no sólo por las ciencias de la vida, más cercanas al derecho que la física, sino también por la propia física cuántica ${ }^{22}$. La tercera razón es el individualismo metodológico o método compositivo de los austríacos, que no es otra cosa que un análisis aplicado a hechos y no a palabras; se trata precisamente de analizar fenómenos complejos como el lenguaje, el mercado, el derecho, descomponiéndolos en sus elementos simples, básicamente los actos humanos individuales. La cuarta razón es el propio subjetivismo: un subjetivismo cognitivo y normativo que logra explicar sin embargo el aspecto objetivo de actividades como la evaluación y la interpretación.

16 H. M. HaRT y A. M. SACKs, The Legal Process. Basic Problems in the Making and the Application of Law (1958), Westbury (N. Y.), Foundation Press, 1994.

17 M. BARBERIS, Stato costituzionale. Sul nuovo costituzionalismo, Modena, Mucchi, 2012.

18 V. VILLA, Una teoria pragmaticamente orientata dell'interpretazione giuridica, Torino, Giappichelli, 2012, 11 .

${ }_{19}$ F. Viola, Natural Law in Twenty Century, en prensa para E. PATTARO y C. Roversi (eds.), Legal Philosophy in the Twentieth Century: The Civil Law World, Springer, Berlin and Heidelberg, 2013. 1994.

20 C. S. Nino, Derecho, moral y política. Una revisión de la teoría general del derecho, Barcelona, Ariel,

${ }^{21}$ J. RAZ, The Authority of Law, Oxford, Oxford U. P., 1979.

22 R. BIN, A discrezione del giudice. Ordine e disordine, una prospettiva «quantistica», Milano, Angeli, 2013. 
La razón principal, sin embargo, me parece la quinta: el evolucionismo cultural especifica la idea genérica de que las instituciones humanas son hechas por los hombres, proporcionando una teoría realista del derecho precisamente en el sentido del realismo jurídico: una teoría del derecho vigente o efectivo, concebido como efecto objetivo de agregación de aplicaciones e interpretaciones subjetivas ${ }^{23}$. Y quizá hay una sexta razón; desde el punto de vista evolucionista es posible explicar la idea del derecho natural superando la falacia - compartida en realidad por el positivismo estándar- de confundir derecho no intencional con derecho natural y derechos humanos con derechos naturales ${ }^{24}$, como vamos a ver en el segundo apartado.

Para resumir el primer apartado. Si se admite un terreno intermedio entre lo natural y lo artificial, entonces valores, normas e instituciones pueden ser concebidos como productos intersubjetivos de actos humanos subjetivos: hechos positivos producidos por seres humanos, aunque no uti singuli, por actos individuales, sino uti universi, por agregaciones de estos actos. Esta perspectiva evolucionista, por un lado, es más específica que el positivismo estándar, y por otro puede verse como una extensión del mismo desde los efectos intencionales a los efectos no intencionales de los actos (legislativos, interpretativos y aplicativos). En todo caso, se trata de una extensión suficientemente amplia como para explicar el núcleo de sentido común al objetivismo ético y al derecho natural, y en particular la idea, incorporada en el lenguaje de los derechos humanos, de que éstos no son creados por el legislador.

\section{SIETE HIPÓTESIS SOBRE LOS DERECHOS HUMANOS}

Entre otras razones de superioridad sobre el positivismo estándar, el evolucionismo tiene también la siguiente: proporcionar una mejor explicación del origen y de la evolución de los derechos humanos. Es verdad, como subrayan los positivistas, que la existencia de los derechos no depende de la estructura del mundo o de la razón humana sino de normas; pero ni siquiera depende, y aquí tienen razón los iusnaturalistas, de una creación ex nibilo de disposiciones por parte de legisladores ordinarios o constitucionales. Los derechos, aunque no sean normas, como a veces se dice, son norm-dependent: se trata precisamente de situaciones de ventaja atribuidas por normas a individuos o grupos ${ }^{25}$. En este apartado voy a proponer algunas hipótesis sobre el origen y la evolución de los derechos, reformulándolas en el léxico evolucionista.

1. El concepto de derechos subjetivos es occidental y moderno. Occidental: «derechos» presenta dificultades de traducción en todas las lenguas extra-occidentales. Moderno: no se encuentran en el Corpus Iuris, fuente casi exclusiva de nuestro conocimiento del derecho romano, distinciones entre usos de «ius» en sentido respectivamente objetivo y subjetivo: al contrario, «iura», en el plural, significa fragmentos

${ }^{23}$ M. BARBERIS, «Interpretación-acto e interpretación-actividad. Nueves extensiones de la teoría genovesa», en prensa para Revista brasileira de filosofía, 2013.

${ }^{24}$ Cfr., p. ej., M. N. RothBARD, L'etica della libertà, trad. it. de The Ethics of Liberty (1982), Macerata, Liberilibri, 1996, 35-39.

25 T. MAZZARESE, «Diritti fondamentali», en U. POMARICI, Atlante di filosofia del diritto, Torino, Giappichelli, 2013, vol. I, 179-217; G. PINO, «Diritti soggettivi», en G. PINO, A. Schiavello y V. Villa (a cura di), Filosofia del diritto. Introduzione critica al pensiero giuridico e al diritto positivo, Torino, Giappichelli, 220-255. 
de derecho jurisprudencial objetivo. Es verdad que los filósofos griegos y los juristas romanos hablan de situaciones de ventajas nominadas que modernamente se llamarían derechos, pero no tienen precisamente nuestro concepto general de derecho subjetivo para clasificarlas: además, ellos hablan del derecho de ser castigado, mostrando claramente que no usan «ius» en nuestro sentido de situación de ventaja ${ }^{26}$.

2. Si es verdad lo que se acaba de decir, hay espacio aquí para una explicación fundamental de los derechos en el sentido de NozicK (cfr. 2.3). Antes de proporcionar esta explicación, sin embargo, cabe distinguir entre el término «derechos», el concepto de derechos y las cosas-derechos. Términos como «iura» y «rights» han empezado a ser usados desde la Edad Media, en expresiones que hoy parecen redundantes porque en realidad eran sólo hendíadis (dos palabras para una cosa) como «iura et libertates» $\mathrm{y}$ «rights and liberties», para reivindicar ventajas consuetudinarias de individuos y grupos. Llamo concepto el sentido de un término, fijado por usos lingüísticos (actos de habla) y registrado por definiciones como las que empiezan a encontrarse desde la Edad media en textos de romanistas y canonistas ${ }^{27}$. Las cosas-derechos no son otra cosa que ventajas aseguradas por normas; en concreto, hay tres tipos de ventajas: microderechos, macro-derechos y derechos-razones.

3. Hay situaciones favorables simples (micro-derechos), complejas, (macro-derechos), y meramente argumentativas (derechos-razones) ${ }^{28}$. Los micro-derechos son los rights de W. HOHFELD: situaciones de ventaja (derechos) correlativas a situaciones de desventaja de otros (deberes) producidas por normas; según una versión de la distinción reglas/principios — versión débil, pero que pretende capturar el núcleo de muchas distinciones fuertes propuestas - los micro-derechos son atribuidos por reglas, normas que dictan directamente la conducta, $\mathbf{y}$ no por principios, normas que orientan la conducta solo indirectamente, por medio de reglas. En general, los derechos en sentido estricto (claims) y las libertades son atribuidos por reglas, mientras que los poderes y las inmunidades son atribuidos por reglas técnicas y principios constitutivos (cfr. 3.2).

Los macro-derechos son conjuntos de micro-derechos establecidos por reglas, reglas técnicas y principios constitutivos: instituciones privadas como la propiedad, o públicas como el voto activo y pasivo. Los derechos-razones, y en particular los derechos humanos, son situaciones de ventaja meramente argumentativas, atribuidas por principios regulativos o directivos, para adoptar la terminología de L. FERRAJOLI (pero solo la terminología). El mismo FERRAJOLI, en efecto, ha criticado la distinción reglas/ principios porque debilitaría la normatividad de la constitución ${ }^{29}$; pero si esta normatividad no fuese débil en sí, no se explicarían las instituciones orientadas a fortalecerla, como la rigidez de la constitución y la justicia constitucional. Por lo demás, la tarea de las distinciones teóricas no es fortalecer algo sino decir si algo es fuerte o débil, incluso a fin de buscar medios para fortalecerlo.

4. Una explicación fundamental del origen de los micro y macro-derechos podría ser proporcionada por el famoso ejemplo de la formación de la propiedad en el

26 M. VilLEY, Le droit et les droits de l'bomme (1983), Paris, Puf, 2009. 2002.

27 B. Tienney, L'idea dei diritti naturali, trad. it. de The Idea of Natural Rights (1997), Bologna, Il Mulino,

28 M. BARBERIS, Ética para juristas, Madrid, Trotta, 2008, cap. I.

29 L. FERRAJOLI, «Constitucionalismo principialista y constitucionalismo garantista», Doxa, 2011, 15-53. 
Treatise of Human Nature de Hume: ejemplo que es el punto de partida implícito o explícito de toda la literatura sobre los property rights de la Law and Economics norteamericana ${ }^{30}$. De hecho sería fácil mostrar que el pasaje de HumE sobre el origen de la propiedad a partir — no de actos intencionales (contratos, promesas), sino- de convenciones establecidas no intencionalmente por actividades ${ }^{31}$, es tan importante como el aún más famoso pasaje Is/Ought; de hecho, aquí se anticipan no sólo teorías económicas de la propiedad como la de H. DEMSETZ ${ }^{32}$, sino, tal como decía, la propia teoría de la evolución de DARWIN.

Aquí voy a proporcionar otra explicación, menos conocida e inspirada por los austríacos: la teoría de la pretensión (claim) de LEONI. En los ensayos de los años sesenta del siglo pasado, hoy publicados bajo el título El derecho como pretensión, LEONI razona a partir de la analogía entre formación de las normas y formación de los precios; ambos nacerían del encuentro de actos subjetivos: respectivamente, pretensiones individuales y evaluaciones subjetivas. Como siempre en el evolucionismo austríaco, los actos subjetivos generan instituciones intersubjetivas como las normas y los precios; el rasgo más relevante de las normas así producidas, al menos según el libertarian LEONI, sería el de ser ajenas a la intervención del legislador.

En la conclusión de LEONI (1964), en efecto, se encuentra una de las pocas referencias a los derechos humanos que hallamos en toda su obra ${ }^{33}$. La única lección todavía válida de la vieja doctrina iusnaturalista de los derechos humanos sería que éstos están substraídos al poder del legislador; los derechos no nacen de los códigos o declaraciones modernas, sino de los conflictos típicos del mundo medieval ${ }^{34}$ : a partir de reivindicaciones de libertades y privilegios consuetudinarios por parte de corporaciones, ciudades, órdenes religiosas... El rasgo polémico de estas declaraciones, como lo dirá JELLINEK (2002), se encuentra sedimentado en textos como la Magna Charta (1215) o, desde el título, la Petition of Rights (1628): el estrato más antiguo de la sedimentación histórica que es el constitucionalismo de los derechos.

5. Aquí hay que avanzar la aclaración más importante sobre la relación entre evolución y derechos humanos. Hasta hoy, el evolucionismo jurídico ha sido tal vez un estudio, y muchas veces una exaltación, de los rasgos «espontáneos» del derecho: la costumbre, el common law, el soft law. Esto no es sólo una limitación innecesaria del enfoque evolucionista: es un error. Si admitimos que el objeto de la metodología austríaca son los efectos no intencionales, pero los efectos de la acción humana intencional, entonces esta misma metodología puede ser aplicada a todo el derecho, sin demasiadas diferencias entre derecho «espontáneo» y derecho «proyectado», y hasta a los derechos humanos. Lejos de ser una abstracción iusnaturalista o iusracionalista, éstos pueden ser la confirmación definitiva de la aplicabilidad general de la metodología evolucionista.

\footnotetext{
30 Sobre la cual, $c f r$. al menos P. CHIASSONI, Law and Economics. L'analisi economica del diritto negli Stati Uniti, Torino, Giappichelli, 1992.

31 D. Hume, A Treatise of Human Nature (1740), Oxford, Clarendon, 1965.

32 Cfr. J. E. KRIER, Evolutionary Theory and the Origin of Property Rights, 2009, http://law.bepress.com/ umichlwps-olin/art 98 .

33 B. LeONI, Il diritto come pretesa, a cura di A. MASALA, Macerata, Liberilibri, 2004, 136-137.

${ }^{34}$ Cfr. todavia B. TIERNEY, L'idea dei diritti naturali, cit. in fine.
} 
No sólo la legislación, derecho intencional y proyectado por definición, sino hasta las declaraciones de estas pretendidas verdades éticas auto-evidentes que serían los derechos humanos, tienen al menos cinco rasgos no intencionales, todos explícita o implícitamente subrayados en mi libro Europa del diritto (2008): 1) la imitación, esta sí casi espontánea, de formulaciones anteriores por constituyentes sucesivos; 2) la migración de las formulaciones de una cultura jurídica a otra; 3 ) la proliferación por generaciones de los derechos, hasta la entropía actual ${ }^{35}$; 4) la interpretación de los textos, es decir, la atribución de sentidos siempre nuevos y en todo caso no previsibles por los autores; por último, 5) la propia posibilidad de considerar los derechos humanos como una adquisición evolutiva de la especie humana ${ }^{36}$ (2.7 in fine).

En particular, creo que he mostrado allí —aunque sin distinguir entre derechos y derechos humanos - que una historia de los derechos en Occidente ha seguido hasta hoy al menos tres regularidades (no leyes, sino generalizaciones empíricas). La primera es la continuidad y la transnacionalidad: los derechos humanos han pasado, sin solución de continuidad, desde la garantía asegurada por los jueces ingleses hasta la Carta comunitaria de Niza, la última, por ahora, de las declaraciones de derechos humanos. La segunda es el giro a la izquierda: los derechos humanos han migrado desde Inglaterra a los Estados Unidos hasta el regreso en la Francia revolucionaria y a los derechos públicos subjetivos alemanes. La tercera es el retraso causado por la anticipación: los países que han llegado temprano al proceso se convierten en los más conservadores.

6. Como consecuencia de un enfoque monista y no pluralista (cfr. 3.1) sobre los valores, siempre se ha ido a la búsqueda de un derecho arquetípico, desde el cual se desarrollarían todos los demás: y al menos desde JELLINEK ${ }^{37}$, se cree que este derecho es la libertad de religión, en particular de conciencia. Desde un punto de vista pluralista y evolucionista, asumo que esa indagación no tiene otro sentido que mitológico o ideológico: en particular, creo que la propia libertad de religión es sólo la abstracción de pretensiones mucho más concretas y antiguas, como la reclamación de la libertas ecclesiae en el incipit de la Magna Charta. Sin embargo, si decidimos jugar al juego de la búsqueda del primer derecho humano, creo que hay un candidato mejor que la libertad religiosa al papel de derecho arquetípico: la property de J. LOCKE.

No se creerá, espero, que esta sea una elección ideológica: el old tory Hume me ha enseñado que la propiedad privada es sólo una convención social conectada a situaciones de escasez de bienes; el new whig FERRAJOLI, a su vez, me ha convencido igualmente de que se trata de un conjunto de poderes más bien que de derechos en sentido estricto. Pero creo también que el dominium romano ha sido una de las instituciones arquetípicas de la llamada tradición jurídica occidental ${ }^{38}$, y que la concepción de la property de LOCKE — en su triple sentido de derecho a la vida, a la libertad y a la

35 R. BIN, Nuovi diritti, vecchie questioni, en prensa.

36 M. BARBERIs, Europa del diritto. Sull'identità della cultura giuridica europea, Bologna, Il Mulino, 2008 (la segunda parte).

37 G. JELlineK, La dichiarazione dei diritti dell'uomo e del cittadino (1895), trad. it. de Die Erklärung der Menschrn- imd Bürgergerrechte, Roma-Bari, Laterza, 2002, 37-46.

38 H. BERMAn, Diritto e rivoluzione. La formazione della tradizione giuridica occidentale, trad. it. de Law and Revolution. The Formation of the Western Legal Tradition (1983), Bologna, il Mulino, 1998; H. P. GLENN, Tradizioni giuridiche nel mondo, trad. it. de Legal Traditions in the World (2000, 2010), Bologna, Il Mulino, 2011. 
propiedad de bienes ${ }^{39}$ — ha sido una de las fuentes de la llamada primera generación de derechos humanos, los derechos de libertad.

7. Como consecuencia de todo esto, desde los derechos subjetivos consuetudinarios originariamente protegidos por los jueces ingleses hasta la dignidad humana declarada por el new constitutionalism ${ }^{40}$ después de Auschwitz, pasando por las llamadas generaciones de derechos de libertad, políticos y sociales, se ha ido sedimentando un discurso de los derechos humanos que tiene algunos caracteres profundamente distorsionados por las dos tradiciones principales de la filosofía del derecho. La tradición iusnaturalista, o mejor dicho jusracionalista, fuente originaria de la doctrina de los derechos humanos, cree que éstos son rasgos inherentes a la naturaleza o a la razón humana, explicando así la naturaleza declarativa del acto de habla con lo cual se formulan ${ }^{41}$ : aunque los especialistas de legal drafting nos enseñen que el indicativo es la manera más fuerte de prescribir.

Los positivistas, como mi amigo TROPER mencionado al principio, aún creen que se puedan crear derechos simplemente formulando normas, como si éstas fuesen selfexecuting, o, un poco mejor, multiplicando las garantías y las garantías de las garantías, como bajo el noble sueño garantista de otro amigo, FERRAJOLI. La verdad la decía el jardinero inglés citado en una ocasión por HAYEK; a la pregunta sobre la mejor manera de tener jardines verdes y florecientes, el jardinero respondía así: es fácil, simplemente se planta la hierba y después se la riega por doscientos o trescientos años. Dicho de otra manera, los derechos humanos no son naturales; para convertirse en adquisiciones evolutivas de la especie deben volverse una segunda naturaleza, por medio de la acción, tanto cooperativa como conflictual, de muchas generaciones de hombres.

\section{METAÉTICA DE LOS DERECHOS HUMANOS}

El rasgo no evolutivo sino evolucionista más importante de los derechos humanos es la interpretación, ordinaria y constitucional: la actividad de atribuir sentidos en los cuales los autores de los textos nunca habían pensado. Como los positivistas jurídicos, creo que la función de las declaraciones de derechos del new constitutionalism ha sido convertir los valores morales en disposiciones jurídicas, a fin de interpretarlas y aplicarlas jurídicamente: y no, al revés, permitir una moral lecture de la constitución. La única certeza, sin embargo, es que para analizar la interpretación constitucional de los derechos humanos sirven algunas herramientas de corte no sólo evolucionista sino también pluralista y especificacionista; los derechos humanos, en particular, deben ser considerados, a la vez, como valores, como principios y como reglas.

1. En lo que se refiere a los derechos naturales como valores, creo que el enfoque evolucionista pueda servir para disolver muchos misterios de la metaética del siglo XX, volviendo a una consideración de los valores más próxima a los orígenes económicos del concepto. Por «valor», aquí, no entiendo nada más que el efecto de agregación

39 J. LOCKE, Trattato sul governo, trad. it. de Two Treatises of Government (1690), Roma, Editori Riuniti, 2006, $\$ 2.5$.

${ }^{40}$ Cfr. todavía M. BARBERIS, Stato costituzionale, cit.

${ }^{41}$ Cfr. todavía M. VILLEY, Le droit et les droits de l'bomme, cit. 
de actos de evaluación individuales: actos subjetivos que determinan criterios de evaluación intersubjetivos, como en el modelo austríaco de la formación de los precios. Este modelo económico es mucho más fino y complejo de que lo se puede presentar aquí ${ }^{42}$; considerado no filológicamente, desde el punto de vista económico, sino filosóficamente, desde el punto de vista metaético de sus consecuencias morales, políticas y jurídicas, la metodología austríaca tiene tres rasgos principales.

El primer rasgo, como se decía, es el subjetivismo, común a todas las concepciones económicas del valor: éste es entendido no como una calidad objetiva de los bienes sino como una calidad atribuida a estos por los sujetos uti singuli (el valor de uso) y uti universi (el valor de cambio). El segundo rasgo, distintivo de los austríacos, es la primacía del conocimiento sobre la evaluación: el valor depende de las preferencias subjetivas (subjetivismo de las preferencias) pero éstas dependen a su vez de las creencias subjetivas (subjetivismo de las creencias). El tercer rasgo, distintivo de HAYEK, es la dispersión del conocimiento entre los sujetos, dispersión que no pueden remediar planificadores centrales que nunca poseen las informaciones suficientes, que sólo lo podría el mercado, como mecanismo intersubjetivo de transmisión de las informaciones por medio de los precios ${ }^{43}$.

Sin embargo, este modelo económico evolucionista sólo puede ayudar a explicar la formación, la evolución y hasta la interpretación de los derechos humanos admitiendo desde el inicio que éstos difieren de los precios y de los valores éticos porque dependen sólo indirectamente de preferencias y creencias individuales y dependen directamente de normas institucionalizadas, es decir producidas y aplicadas por instituciones. Del mismo modo que los derechos en general deben su existencia a su aplicación por los jueces de common law y después a su reconocimiento por el parlamento inglés, así los derechos humanos no habrían existido - al menos no como derechos jurídicos, sino sólo como derechos morales — sin una larga serie de declaraciones nacionales y supranacionales, y por su implementación por instituciones estatales y supraestatales ${ }^{44}$.

Para la formación y la evolución de los derechos humanos, atribuidos a todos los hombres como tales, han sido necesarios documentos: textos originariamente sólo políticos y morales, como las Declaraciones universales desde la francesa de 1789 a la de la ONU de 1948 o, desde 1945 —-fecha de inicio del desarrollo del new constitutionalism - también jurídicos, como la Convención europea de los derechos y de las libertades fundamentales del Consejo de Europa (1950) y la Carta de los Derechos Fundamentales de la Unión Europea (2000). Se trata de documentos jurídicos en la medida en que se interpretan o aplican por jueces constitucionales, europeos, internacionales e incluso ordinarios; este era ya el criterio de hecho adoptado por John Austin cuando negaba la juridicidad del derecho internacional, hasta entonces nunca aplicado por los jueces.

42 Cfr. al menos F. WIESER, «The Austrian School and the Theory of Value», en The Economic Journal, 1891, 1, y E. BOHM-BAWERK, «The Ultimate Standard of Value», Annals of the American Academy of Political and Social Sciences, 1894-1895, 5, 149-208.

43 V. J. VANBERG, «Austrian Economics, Evolutionary Psychology and Methodological Dualism: Subjectivism Reconsidered», 2004, en hdl.handle.net/10419/4336.

44 Th. BuERGHENTHAL, «The Evolving International Human Rights Systems», American Journal of International Law, 2006, 100, 783-807. 
En la misma medida, la discusión política y moral sobre los derechos humanos se ha convertido en interpretación constitucional: expresión que indica no tanto la atribución de sentido a textos constitucionales, en sí no demasiado diferente de la interpretación de la ley, sino el conjunto de argumentos típicos de los jueces constitucionales, y las técnicas utilizadas también por los legisladores como la especificación, la ponderación y el control de proporcionalidad (cfr. 3.3). A la antigua disputa entre objetivistas y subjetivistas metaéticos se superpone la nueva disputa interpretativa entre formalistas y escépticos interpretativos: de hecho, los objetivistas éticos tienden a convertirse en formalistas, y los subjetivistas en escépticos. Ambas disputas creo que pueden ser relativizadas y superadas desde el enfoque austríaco: las evaluaciones e interpretaciones son sin duda subjetivas, pero producen valores y normas objetivos o al menos intersubjetivos.

Una discusión sólo en apariencia técnica, y en todo caso más relevante para la interpretación constitucional, se refiere a la distinción entre evaluaciones y normas. La idea dominante en la ética analítica desde R. HARE ${ }^{45}$ hasta C. AlChOURRÓN, E. BulYGin y L. FERRAJOLI, ha sido que las evaluaciones son o implican prescripciones. Con Carlos Nino creo, por el contrario, que juicios de valor y normas tienen sentidos diferentes ${ }^{46}$; las evaluaciones abstractas implican evaluaciones concretas, pero no normas: hay aquí una barrier to implication ${ }^{47}$. Lo mismo ocurre cuando las evaluaciones políticas y morales en términos de derechos humanos son formuladas en textos jurídicos como las declaraciones del new constitutionalism; aquí las evaluaciones se convierten en normas que, sin embargo, no son ni implican prescripciones: los principios.

2. En cuanto a los derechos humanos como principios, M. AtienZa y J. Ruiz MANERO ${ }^{48}$, y también el último FERRAJOLI ${ }^{49}$, hablan de su carácter «bifronte», evaluativo y normativo, y G. SARTOR de «normas de valor» ${ }^{50}$. Yo creo que las mismas formulaciones — como «la vida es sagrada», «la libertad es inviolable», «los ciudadanos tienen un derecho al trabajo»-1) pueden expresar dos tipos de principios diferentes, que con FERRAJOLI llamo regulativos y directivos; 2) que ambos tipos son normas pero, como las evaluaciones, no implican reglas (desde «la vida es sagrada» se puede deducir otro juicio de valor, como «la vida de Caín es sagrada», pero no, sin especificaciones ulteriores, la regla abstracta «no matar» ni la regla concreta «no matar a Caín»); 3) que ambos tienen consecuencias diferentes en diversos contextos institucionales, y a menudo se trata de evaluaciones casi sin consecuencias jurídicas en las constituciones flexibles del llamado Estado legislativo, y de normas de principio, con una normatividad menor que las reglas, en las constituciones rígidas del llamado Estado constitucional.

45 R. M. Hare, Il linguaggio della morale, trad. it. de The Language of Morals (1952), Roma, Astrolabio, 1968.

46 C. S. Nino, La validez del derecho, Buenos Aires, Astrea, 1985, 116-117.

47 Cfr. G. Restall y G. Russel, Barriers to Implication, 2012, bttp//consequently.org/papers/barriers.pdf (ensayo señalado por A. SARDO).

48 M. Atienza y J. Ruiz Manero, Las piezas del derecho, Barcelona, Ariel, 1996, 123-142. 2013.

49 Cfr. L. Ferrajoli, Dei diritti e delle garanzie. Conversazione con Mauro Barberis, Bologna, Il Mulino,

50 G. SARTOR, «La logica della proporzionalità: il ragionamento con magnitudini non numeriche», Rivista di filosofia del diritto, 2012, 342 ss. 
Hay al menos tres tipos de principios; todos ellos se dirigen sólo indirectamente a los ciudadanos y directamente al legislador, orientando más o menos su discreción. Los principios regulativos declaran derechos humanos que deben ser respetados por medios jurídicos, como los derechos a la dignidad, a la vida, a la libertad, y muchos de los derechos llamados equívocamente sociales, como el derecho a la salud; no hay diferencias jurídicas sino sólo históricas y políticas entre estos derechos y los llamados derechos de libertad o políticos: todos atribuyen derechos individuales que pueden ser garantizados judicialmente. Sin embargo, la misma disposición en materia de salud puede expresar, conjuntamente o por separado, un principio regulativo que garantiza un derecho individual, o un principio directivo que promueve un interés colectivo.

Los principios directivos (policies, Optimierungsgebote) se formulan en términos de derechos pero no garantizan verdaderos derechos individuales, en relación con los cuales se pueda actuar judicialmente, sino que fijan intereses colectivos promovidos sólo políticamente, eligiendo los medios para conseguirlos. Mientras la discreción del legislador para garantizar los principios regulativos es débil, y el control de constitucionalidad fuerte, aquí sucede al revés, la discreción para promover los principios programáticos es fuerte, y el control de constitucionalidad débil: la elección del medio por la mayoría parlamentaria no podría ser controlada judicialmente sin vaciar la propia democracia. El llamado derecho al trabajo, es decir el interés colectivo al pleno empleo, sin duda no puede ser considerado un sinsentido, como piensan HAYEK y sus seguidores, sino como un objetivo que el legislador - las diferentes mayorías parlamentarias - pueden perseguir eligiendo medios tan diferentes como la intervención estatal o el mercado.

Los principios constitutivos, como el que establece el carácter republicano o monárquico del Estado, son conjuntos de reglas técnicas y de normas constitutivas, e instituyen poderes públicos (como el voto) y privados (como la propiedad) que pueden, a su vez, ser calificados como derechos humanos, pero son básicamente poderes. Si no me equivoco, todos los principios, regulativos, directivos y constitutivos, comparten sólo dos características. En primer lugar, todos son meta-normas, es decir normas que orientan la producción o el contenido de otras normas: los principios regulativos fijan los valores que las leyes deben respetar, los principios directivos los objetivos que las leyes deben perseguir, los principios constitutivos los poderes que producen las otras normas. En segundo lugar, precisamente como sucede con los valores cuya formulación comparten, los principios no implican sino justifican reglas.

3. En cuanto a las reglas, éstas siguen siendo el verdadero núcleo del derecho; para aplicarse a la conducta, los principios deben convertirse en reglas, y los derechosrazones como los propios derechos humanos deben convertirse en micro- y macroderechos. El rasgo genéricamente evolutivo de este proceso está capturado por teorías tan diferentes como la nomodinámica de H. KELSEN, el Legal process, la teoría de la justicia de J. RAWLS y todas las teorías no formalistas de la interpretación, que se llamen dinámicas, como la de W. ESKRIDGE ${ }^{51}$ o pragmáticas, como la de VILLA. El rasgo específicamente evolucionista del mismo proceso, en cambio, ha sido esquematizado

\footnotetext{
51 W. N. Jr. Eskridge, Dynamic Statutory Interpretation, Cambridge (Mass.), Harvard U. P., 1994.
} 
por N. LUHMANN en los términos darwinianos de mutación (legislación), selección (aplicación por los jueces), retención (interpretación por la doctrina) ${ }^{52}$.

Para adaptar este modelo, en sí adecuado sólo al Estado legislativo, al Estado constitucional se debe añadir un cuarto nivel: precisamente el nivel constitucional de los derechos humanos, como valores éticos seleccionados por la evolución cultural e institucionalizados por las declaraciones de derechos. La llamada interpretación constitucional, desde este punto de vista, puede considerarse el proceso por el cual los derechos humanos, que en sí serían sólo derechos-razones formulados por principios genéricos, se convierten en micro- y macro-derechos garantizados por reglas. Las argumentaciones más utilizadas por todos los participantes en el proceso son la especificación, la ponderación y el control de proporcionalidad: técnicas con referencia a las cuales la metodología evolucionista debe ser integrada por las metaéticas especificacionistas y pluralistas.

Llamo especificación, adoptando el léxico del especificacionismo metaético ${ }^{53}$, al razonamiento que extrae reglas específicas a partir de principios genéricos: un razonamiento no deductivo, como lo es en cambio la concretización de reglas concretas a partir de reglas abstractas. Los constituyentes pueden compartir un acuerdo no teorizado ${ }^{54}$ acerca del concepto de la vida, a pesar de sus diferentes concepciones ${ }^{55}$, y adoptar el principio genérico «la vida es sagrada» aunque no estén de acuerdo acerca de sus aplicaciones a casos como el aborto, el suicidio asistido, la legítima defensa, el estado de necesidad, la pena de muerte, el homicidio del enemigo en la guerra... En todas estas aplicaciones, en efecto, el valor-principio de la vida choca con otros valoresprincipios relevantes (salud, dignidad, defensa de la patria...).

La proliferación de derechos humanos desde la property de LOCKE hasta los derechos de cuarta o quinta generación produce inevitablemente conflictos; como subraya el llamado pluralismo de los valores ${ }^{56}$, estos conflictos no son una condición patológica, sino fisiológica de los valores, aunque la misma evolución pueda producir jerarquías parciales y relativamente estables entre ellos. Para especificar principios, en todo caso, puede ser necesario solucionar conflictos intra-principios (p. ej., entre la vida de quien mata y la de quien es muerto por defensa legítima) o inter-principios (p. ej., entre la vida del feto y la salud de la mujer): y la única manera de no ocultar estos conflictos es la ponderación. Esta puede ser representada, à la R. GUASTINI, como una preferencia por un valor-principio-derecho en lugar de otro, pero lo es mejor como una conciliación entre valores-principios-derechos relevantes.

Creo que esta segunda representación, aunque compatible con la primera, es mejor por al menos tres razones. La primera es que explica la propia denominación de ponderación, que supone la relevancia de ambos valores en juego, y no sólo del valor

52 N. Luhmann, La differenziazione del diritto, trad. it. de Ausdifferenzierung des Rechts (1981), Bologna, Il Mulino, 1981, 35-60.

${ }_{53}$ Cfr. R. SCHAFER-LANDAU, «Specifying Absolute Rights», Arizona Law Review, 1995, 37, 209-225, y C. LuZZATI, Principi e principi. La genericità nel diritto, Torino, Giappichelli, 2012.

54 C. Sunstein, Designing Democracy. What Constitutions Do, Oxford, Oxford U. P., 2001, 49-66.

55 R. Dworkin, La giustizia in toga, trad. it. de Justice in Robes (2006), Roma-Bari, Laterza, 2010, 15, 153-203.

56 I. BerLin, Due concetti di libertà, trad. it. de Two Concepts of Liberty (1958), Milano, Feltrinelli, 2000, 71-77. 
que prevalece al final. La segunda razón es que permite explicitar todas las reglas que solucionan el conflicto y no sólo una: en el caso del aborto, por ejemplo, no sólo la regla que permite el aborto dentro de los tres meses a partir de la concepción, sino también la otra que lo prohíbe después de ese término ${ }^{57}$. La tercera y quizá más importante razón es precisamente representar la ponderación en términos económicos y razonables, como lo hace en principio R. ALEXY ${ }^{58}$, y no como un conjunto de decisiones subjetivas e irracionales.

Esta representación de la ponderación como conciliación permite considerar conmensurables valores que de otra manera serían inconmensurables, como dirían los pluralistas, o no negociables, como diría la Iglesia. C. SCHMITT cree criticar la ponderación diciendo que hace conmensurable lo inconmensurable ${ }^{59}$, pero esta es precisamente su virtud: asignar valores cuantitativos, incluso ficticios, a los derechos en conflicto es la única manera de ponderar costes y beneficios bajo criterios como el llamado principio de proporcionalidad. Este criterio, seguido por el Tribunal constitucional alemán desde el fallo Luth (1958), permite sacrificar un derecho humano a otro sólo si este sacrificio es necesario, adecuado y proporcional: que me parece una técnica razonable de solución de los conflictos, siempre que no pretenda reducir los derechos humanos a valores económicos, o la interpretación constitucional a la búsqueda de una sola solución.

Dejando de lado las viejas concepciones iusnaturalistas y positivistas estándar, este ensayo ha propuesto adoptar una concepción positivista refinada que puede calificarse de evolucionista, especificacionista y pluralista. Evolucionista: los derechos humanos, como todos los valores, son agregaciones de evaluaciones subjetivas, que pueden ser institucionalizadas jurídicamente y objetivamente por las constituciones. Especificacionista: los derechos humanos son declarados por principios genéricos que admiten especificaciones diferentes. Pluralista: los derechos humanos son valores plurales y siempre virtualmente conflictivos, y para solucionar el conflicto necesitan técnicas como la ponderación y el juicio de proporcionalidad. Estas concepciones son realistas y no optimistas, pero precisamente por esta razón no debilitan sino fortalecen la lucha para convertir los derechos en adquisiciones evolutivas de la especie humana.

57 Cfr. J. J. Moreso, «Conflictos entre principios constitucionales», en M. CARBOnELl (comp.), Neoconstitucionalismo(s), Madrid, Trotta, 2003, 99-121, y D. MEndonçA, Los derechos en juego. Conflicto y balance de los derechos, Madrid, Tecnos, 2003.

58 R. AleXY, «Constitutional Rights, Balancing and Rationality», Ratio Juris, 2003, 16, 131-140.

59 K. Schmit, La tirannia dei valori, trad. it. de Die Tyrannie der Werte (1959), Milano, Adelphi, 2008. 